\title{
Why do Spanish households separate their e-waste for proper disposal? An econometric analysis
}

\author{
Fernando Arbués ${ }^{1}$ (1) - Inmaculada Villanúa ${ }^{2}$ \\ Received: 4 May 2021 / Accepted: 8 August 2021 / Published online: 1 September 2021 \\ (C) The Author(s) 2021
}

\begin{abstract}
Improving e-waste separate collection rates is of the utmost importance to achieve the environmental targets set in the Sustainable Development Goals. Therefore, this paper aims to identify the factors influencing the intentions of Spanish households to separate their e-waste for proper disposal. To this end, we carry out an econometric analysis revealing that the preoccupation with environmental issues is an endogenous regressor, so a bivariate model is required to avoid inconsistent results. The analysis shows that environmental concern and the origin of the individuals are relevant factors that influence the e-waste separation decision. Additionally, we observe an interaction between age and city size, so the effect of one of these factors on the probability of separating e-waste depends on the other factor. Another important result is that several socio-economic variables and knowledge of environmental issues only indirectly affect attitudes, by way of environmental concern. In summary, this study offers a useful methodology to policymakers who have to deal with e-waste management, allowing them to identify the priority groups on which should be focused, as well as to design specific measures tailored to their characteristics.
\end{abstract}

Keywords e-waste $\cdot$ Households' behaviour $\cdot$ Bivariate probit model $\cdot$ Environmental concern $\cdot$ Interaction effects $\cdot$ Sustainable Development Goals

\section{Introduction}

The use of electrical equipment and electronic devices has become a typical feature of modern society. A result of the increasing consumption of these products (laptops, monitors, refrigerators, smartphones, etc.) has been that the waste they generate (e-waste) which is considered as the fastest growing waste stream in the world, with 53.6 million tonnes generated in 2019, and it is expected to exceed 74 million tonnes by

$\underline{\text { Responsible Editor: Baojing Gu }}$

Fernando Arbués

farbues@unizar.es

Inmaculada Villanúa

villanua@unizar.es

1 Aragon Public Economics Research Group, Institute of Research into Environmental Sciences (IUCA), University of Zaragoza, Violante de Hungría 23, 50009 Zaragoza, Spain

2 Aragon Growth, Demand and Natural Resources Research Group, Department of Economic Analysis, University of Zaragoza, Gran Vía, 2, 50005 Zaragoza, Spain
2030 (Forti et al. 2020). It is noteworthy that e-waste is a non-homogeneous and complex mixture of diverse hazardous materials that may pose environmental and health risks if not properly collected, treated, and recycled or otherwise disposed of. Moreover, within the paradigm of a circular economy, the separate collection of e-waste is important in terms of recovering valuable and scarce materials, especially copper, and precious metals. ${ }^{1}$

Similar to other developed countries, e-waste is a major concern for European Union (EU) environmental policies focused on reducing its ecological footprint and promoting a circular economy model of economic growth. According to the European Commission (2020), e-waste is growing at 3\% to $5 \%$ per year, three times faster than the average waste stream, and EUROSTAT (2021a) shows that only $38.9 \%$ is properly recycled. In this context, it should be noted that households are the main source of e-waste in all EU countries (EUROSTAT 2021b). This is the case in Spain, where $87 \%$ of

\footnotetext{
${ }^{1}$ The composition of e-waste varies widely, depending on the type and age of the equipment. However, e-waste is usually composed of metals (copper, iron, silver, gold, nickel, and tin, among others), plastic, and refractory oxides. For more details about e-waste composition and the potential associated contaminants, see Forti et al. (2020).
} 
e-waste collected in 2018 , i.e. 279,100 tons, came from households, while the amount from other sources was 41,522 tons (EUROSTAT 2021b). Furthermore, between 2008 and 2018, 7.172 million tons of electrical and electronic devices for households were put on the market (EUROSTAT 2021b), which indicates the potential e-waste available from Spanish households in the coming years.

To improve the collection and recycling of electrical and electronic equipment, and thus tackle this fast-increasing waste stream, the EU put in place, in 2003, the European Directive on waste electrical and electronic equipment, revised in 2012 (European Union 2012). The Directive requires Member States to 'adopt appropriate measures to minimize the disposal of e-waste in the form of unsorted municipal waste, to ensure the correct treatment of all collected e-waste, and to achieve a high level of separate collection of e-waste' (European Union 2012; Art.5 §1). Furthermore, the Directive sets criteria and targets for the collection, treatment, and recovery of e-waste (European Union 2012; Arts. 5, 6 and 7). In this context, meeting the targets set in the Directive requires that Member States 'adopt appropriate measures so that consumers participate in the collection of e-waste and to encourage them to facilitate the process of re-use, treatment and recovery' (European Union 2012; Art.14 §3). In Spain, the implementation of this European Directive is based on the Royal Decree on the Disposal of Electrical and Electronic Equipment (Official State Gazette 2015). In accordance with it, the minimum target for e-waste collection from households met in 2019 was $395,422,100.49 \mathrm{~kg}$ (MITECO 2020), which represents an increase of 50.65\% of the e-waste collected from households in 2017.

Furthermore, increasing levels of e-waste is a major challenge for the achievement of Sustainable Development Goals (SDGs) set out in the 2030 Agenda for Sustainable Development (United Nations 2015), particularly those related to 3.9, 8.3, 8.8, 11.6, 12.4, and 12.5 specific targets (United Nations 2015).

In this context, where the adoption of measures to promote the separate collection of e-waste becomes a priority, the purpose of this study is to identify the behaviours and characteristics of households that influence the participation of Spanish households in the separate disposal of e-waste. Note that the household characteristics and their attitudes towards separating and recycling different kinds of waste is a determinant issue for designing effective measures addressing waste separation and collection as pointed out by many works, such as Aprile and Fiorillo (2019), Dwivedy and Mittal (2013), Saphores et al. (2012), and Zen et al. (2014).

The choice of Spain for our analysis is relevant for two major reasons: first, because Spain is currently showing great interest in the achievement of the SDGs. However, although for some years now, national, regional, and local Spanish authorities have been implementing several measures to promote pro-environmental attitudes (such as e-waste separation), as we have pointed out above, in Spain, a significant improvement of separate e-waste collection rates is needed (European Commission 2019), and secondly, because Spain is located in the Mediterranean Basin, a region highly exposed to significant environmental risks due to climate change (Pausas and Millán 2019), so improving e-waste recovery and recycling rates can generate important benefits by reducing $\mathrm{CO}_{2}$ emissions to the atmosphere.

Thus, the objective of this paper is to analyse the participation of Spanish households in e-waste separation and disposal. For this purpose, we estimate a binary model containing two sets of explanatory variables: personal and household characteristics and environmental attitudes, including the preoccupation with environmental issues. Many studies which deal with recycling issues using binary models can be found in the literature. The usual practice in these works is to include the attitudinal factors related with the environment as explanatory variables in the model directly. Nevertheless, including these variables, which are choices made by respondents, directly in the model, an endogeneity problem can arise. Thus, the possible endogeneity of one of the regressors requires specifying a two-equation binary model (bivariate probit model), in order to obtain adequate estimates. In this kind of models, we can distinguish direct and/or indirect effects of the regressors on the dependent variable, the last ones obtained through the endogenous regressor. Additionally, we introduce as regressors the interaction effects between two qualitative factors in the proposed model. Their inclusion allows us to study how a change in one of these factors can be affected by the value of the other.

Hence, the main contributions of our empirical work can be summarized as follows: (1) the estimation of a bivariate probit model with interaction effects to identify the factors determining the correct disposal of e-waste, which has not been used in the context of e-waste studies; (2) since, as we have indicated above, households are an important source of e-waste in most European countries, the results of our analysis can be very useful in exploring ways of reducing the percentage of such waste that households dispose of.

The rest of the paper is organized as follows: Section 2 includes a literature review of previous empirical works focused on household waste management behaviour. Next, Section 3 offers general description of the data and the variables used in the study as well as an explanation of the most important issues of our analytical procedure. The findings of the econometric estimation of the proposed model are presented and discussed in Sections 4 and 5, respectively. In Section 6, we report some concluding remarks. 


\section{Literature review}

A significant number of empirical works have addressed the factors influencing the separate collection of waste by households focusing on two groups of variables: socio-economic and demographic variables and psychological determinants of pro-environmental behaviours (environmental awareness, social norms, habits, etc.). ${ }^{2}$

In the first group, as Do Valle et al. (2004) and Saphores et al. (2012) point out, the most commonly considered are income, age, gender, and education level. Other variables, such as household size, the labour status of the individuals, the place of birth of the individuals, the kind of city living, and dwelling characteristics, are also included in several studies with the purpose of detecting the effects of other relevant socio-economic factors on residential waste management (see Table 1). In the second group, the most common variables found in reviewing the literature can be grouped in three categories: general attitudes towards the environment, perceptions related to recycling, and social influences (see Table 1).

Nevertheless, as noted in Arbués and Villanúa (2016) and Hansmann et al. (2006), the relationship observed between these variables and waste separation of households appears to be ambiguous. For example, with regard to income, Aprile and Fiorillo (2019), Dwivedy and Mittal (2013), or Song et al. (2012) show that a higher income increases the recycling probability, while others, such as Do Valle et al. (2004), Saphores et al. (2012), and Wang et al. (2011), suggest that the influence of income on recycling behaviour is reduced. As Hornik et al. (1995) and Arbués and Villanúa (2016) indicate, this is mainly due to these studies being carried out in different geographical areas by researchers who assume different perspectives in their analysis (socio-economic, sociological/psychological, and technical) concentrating their attention on different sets of variables.

From a methodological perspective, it is observed that an assortment of analytical procedures is used to estimate the relationship between disposal behaviour of households and the set of explanatory variables considered in the study. As we can see in Table 2, methods used range from general statistical techniques (e.g. frequency analysis and Chi-squared test) to regression-based methods, which are used in this paper.

Among regression-based procedures, logit binary response models are the more widely used in the empirical works revised. Only few studies estimate probit models (see Table 2). In this paper, as we have indicated above, we estimate a bivariate probit model in order to address the endogeneity that

\footnotetext{
${ }^{2}$ A broad analysis of the relevant literature on household recycling can be found in Hornik et al. (1995) and Saphores et al. (2006). In the specific field of e-waste, an in-depth literature review can be found in Pérez-Belis et al. (2015a).
}

could arise when a single logit or probit model is estimated. This is an approach that only few previous studies, such as Arbués and Villanúa (2016), Crociata et al. (2015), and Tadesse (2009), have considered. In our case, in contrast to these previous works, we include as regressors in the model some interaction variables (the product of the dummies of two different factors). As far as we know, this kind of model (bivariate probit model with interactions) has not been applied to analyse e-waste recycling behaviours.

\section{Data and methods}

\section{Data}

Our dataset is extracted from the 'Survey on Households and the Environment 2008' carried out by The Spanish Statistical Institute (INE) on a random sample of 27,832 Spanish households, in each of which a cooperating person was selected. The aim of this survey was analysing environmental attitudes and patterns in Spain (INE 2009).

The data collection method used in this survey was the personal interview, although in some cases the possibility of providing the information online or on a free telephone line was offered (INE 2009).

To ascertain the environmental awareness of individuals, the survey includes a set of preliminary questions with the aim of gathering socio-economic and demographic information (income, age, education, country of birth, etc.) about the individuals selected. Regarding environmental awareness, the respondents were asked about environmental concerns, detection of environmental problems, and knowledge of environmental campaigns. Furthermore, to ascertain the attitudes of individuals about their waste management, they were also asked about the sorting and deposit at specific collection points of a set of wastes, among which were e-waste ${ }^{3}$.

The files containing the microdata of this survey are available at INE (2010).

\section{Variable specification}

As we have indicated above, the dependent variable of our empirical study, that we call Separate, is a binary variable. It takes value 1 for households that collect separately their ewaste and 0 otherwise. To explain this variable, we have considered two sets of factors: personal and household characteristics and environmental attitudes. These potential explanatory factors are summarized in Table 3. Most of them are qualitative, so they must be quantified by using dummy variables. Table 3 shows both the factors (first column) and the

\footnotetext{
${ }^{3}$ For more details about the target characteristics of this survey, see INE (2009).
} 


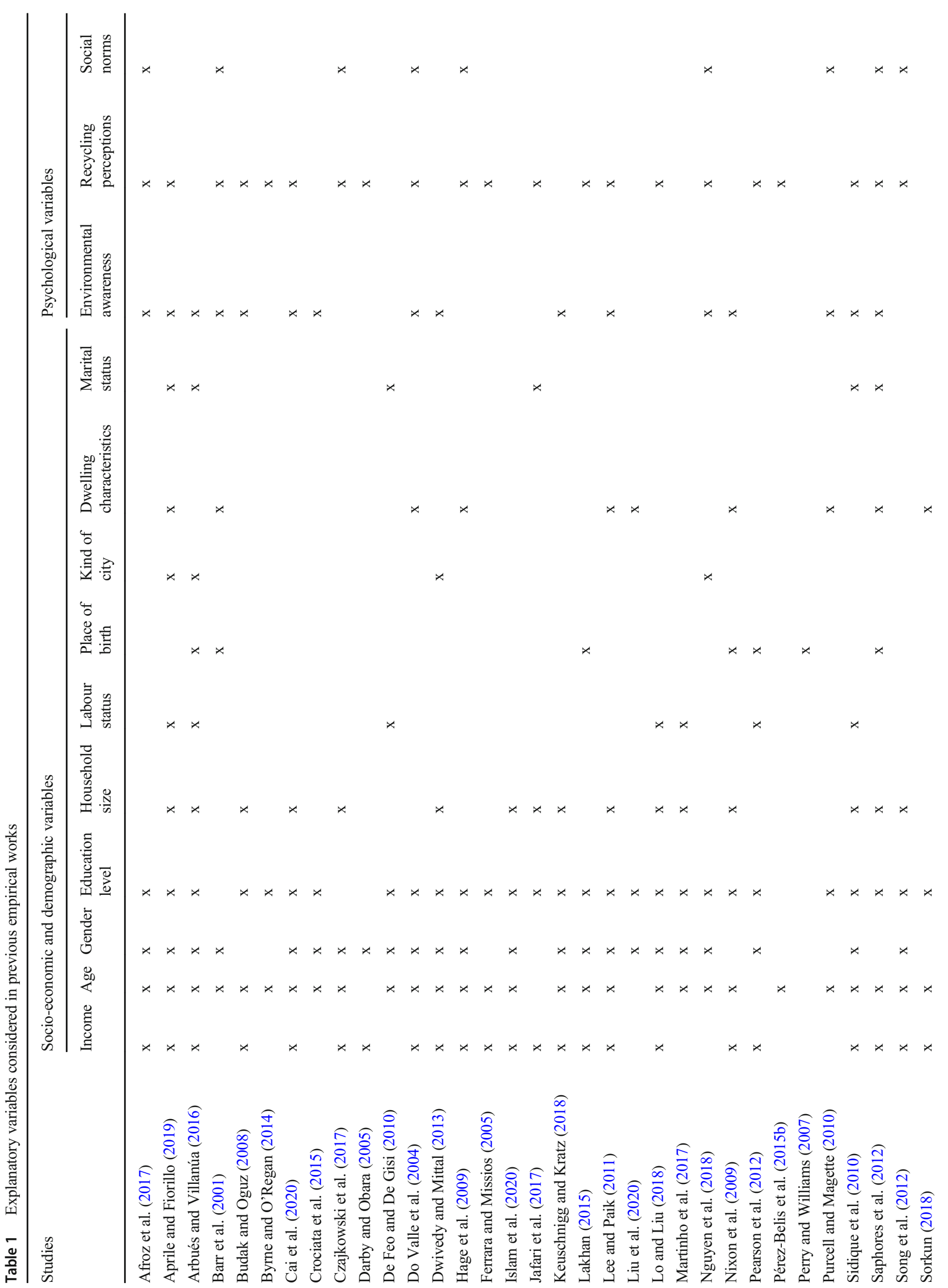




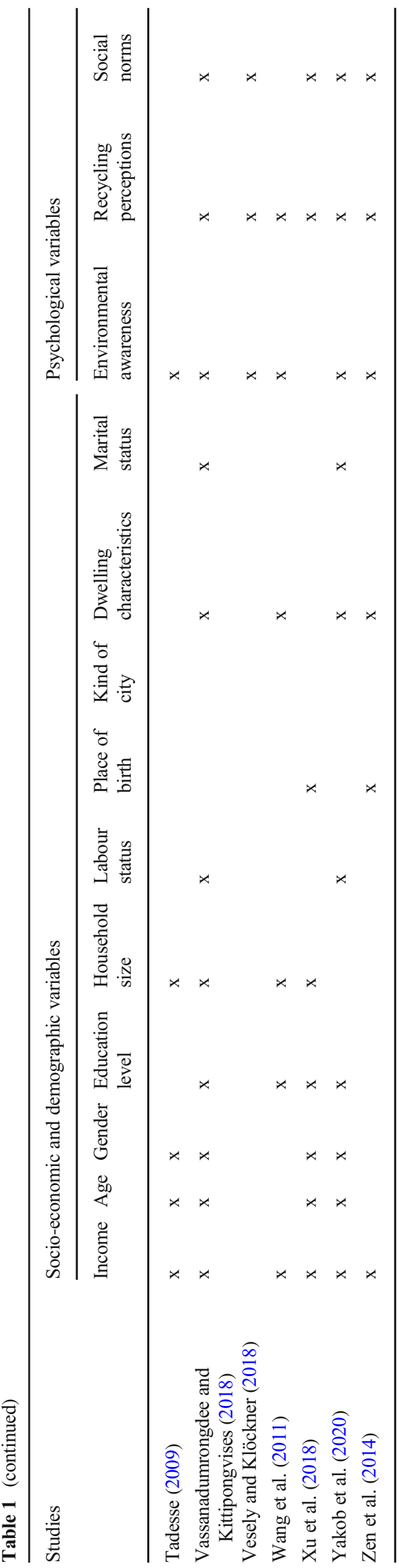

corresponding quantitative variables (second column), together with its description (third column). Some of the factors have more than two categories, so we need more than one dummy to capture its effect. ${ }^{4}$ It is noteworthy that dummy variables corresponding to the Age factor are not mutually exclusive and can equal 1 jointly if people from different ranges of age lives in a household.

In Table 4, the summary statistics of the variables are shown. Most respondents were born in Spain, were working, and had the basic educational attainment. The information concerning household earnings suggest that households belong mostly in the middle class $(54.7 \%)$. Regarding age, a significant percentage of households had some member in the age range between 30 and 60 years old. The rest of the socio-economic variables (gender, city size, and marital status) were evenly distributed, and the average household size was 2.596. The information corresponding to the environmental attitudes show that the majority of households $(78.3 \%)$ responded affirmatively to the question on whether they were concerned about the environment. Moreover, $61.5 \%$ of the respondents stated that they had knowledge of any environmental awareness campaign (saving water, energy, recycling, etc.) in the last year. Finally, among the sample households, only $26 \%$ reported that they had some environmental problem (pollution, noise, bad smells, etc.) in their surroundings.

\section{Analytical procedure}

In order to explain the dependent binary variable Separate, the binary model that we specify has the general expression:

$p=F(\mathbf{x} \beta)$

being $p$ the probability of separating e-waste, that is, $p=$ $\operatorname{pr}($ Separate $=1), \mathbf{x}$ the regressor vector, and $\beta$ the parameter vector. Moreover, $F$ is a cumulative distribution function, which can be normal, if the binary model is a probit model $p$ $=\Phi(\mathbf{x} \boldsymbol{\beta})$, or logistic, if we specify a logit model $p=\Lambda(\mathbf{x} \boldsymbol{\beta}){ }^{5}$ Expression (1) has an underlying latent model that can be written as:

$Y^{*}=\mathbf{x} \beta+u$

where $Y^{*}$ is a non-observable variable representing level of utility or satisfaction and $u$ is the error term, whose distribution normal or logistic leads to the probit and logit model above mentioned. Thus, the binary variable Separate adopts value 1 if $Y^{*}>0$ and value 0 if $Y^{*}<0$.

The adequate estimation procedure for these models is the maximum likelihood (ML), which requires solving a

\footnotetext{
${ }^{4}$ It is well known that one of the categories corresponding to the same factor will be not included in the model, being the "control group".

${ }^{5}$ The logistic cumulative distribution function is $\Lambda(\mathbf{x} \beta)=\frac{e^{\mathrm{x} \beta}}{1+e^{\mathrm{x} \beta}}$.
} 
Table 2 Analytical procedures applied in previous works

Studies

Afroz et al. (2017)

Aprile and Fiorillo (2019)

Arbués and Villanúa (2016)

Barr et al. (2001)

Budak and Oguz (2008)

Byrne and O'Regan (2014)

Cai et al. (2020)

Crociata et al. (2015)

Czajkowski et al. (2017)

Darby and Obara (2005)

De Feo and De Gisi (2010)

Do Valle et al. (2004)

Dwivedy and Mittal (2013)

Ferrara and Missios (2005)

Hage et al. (2009)

Islam et al. (2020)

Jafari et al. (2017)

Keuschnigg and Kratz (2018)

Lakhan (2015)

Lee and Paik (2011)

Liu et al. (2020)

Lo and Liu (2018)

Martinho et al. (2017)

Nguyen et al. (2018)

Nixon et al. (2009)

Oskamp et al. (1998)

Pearson et al. (2012)

Pérez-Belis et al. (2015b)

Perry and Williams (2007)

Purcell and Magette (2010)

Sidique et al. (2010)

Song et al. (2012)

Sorkun (2018)

Tadesse (2009)
Analytical procedures

Regression-based procedures

General statistics procedures

Logistic regression

Probit model

Bivariate probit model

Chi-squared test

Cluster analysis

Principal component analysis

Logistic regression

Frequency analysis

Cross tabulation

Chi-squared test

Binary regression model

Bivariate probit model

Hybrid multinomial logit

Hybrid mixed logit

Frequency analysis

Cross tabulation

Chi-squared test

Frequency analysis

Logistic regression

Principal component analysis

Logistic regression

Ordered probit model

Ordered probit model

Multinomial logistic regression

Logistic regression

Binary logistic regressions

Ordinary least squares

Ordinary least squares

Rank-ordered logit model

Hierarchical multiple regressions

Logistic regression

Ordinal logistic regression

Logistic regression

Poisson regression model

Logistic regression

Bivariate probit model
Frequency analysis

Cross tabulation

Chi-squared test

Unpaired $t$-test

Confirmatory factor analysis Structural equation model

Frequency analysis

Cross tabulation

Chi-squared test

Factor analysis

Analysis of moment structures

Principal component analysis

Principal component analysis

Chi-squared test

Independent group $t$-test

Sobel test

Chi-squared test

Frequency analysis

Factor analysis

Confirmatory factor analysis

Structural equation model

Bootstrapping approach 
Table 2 (continued)

Studies

Analytical procedures

Regression-based procedures

General statistics procedures

Vassanadumrongdee and Kittipongvises (2018)

Vesely and Klöckner (2018)

Wang et al. (2011)

$\mathrm{Xu}$ et al. (2018)

Yakob et al. (2020)

Zen et al. (2014)

\section{Logistic regression}

Logistic regression

Logistic regression

Multiple regression
Factor analysis

One-way ANOVA test

Factor analysis

Frequency analysis

Factor analysis

Analysis discrimination method nonlinear equation system, through a nonlinear optimization algorithm. The ML procedure provides consistent estimates of $\beta$ unless one (or more) of the regressors is not exogenous.

The coefficients included in $\beta$ only provide the sign of the change in probability $p$ under changes in the explanatory factors. Therefore, in order to quantify these changes, it is necessary to calculate the marginal effects as $\partial p / \partial X_{j}$ or $\Delta p / \Delta X_{j}$ for continuous and discrete regressors, respectively.

For a generic dummy variable $D_{j}$, with estimated coefficient $\widehat{\beta}_{D_{j}}$, and assuming a probit model $(F=\Phi)$, the corresponding marginal effect from changing $D_{j}$ from zero to one can be calculated as:

$$
\begin{aligned}
\Delta \widehat{p} / \Delta D_{j} & =\operatorname{pr}\left(Y_{1}=1 \mid D_{j}=1\right)-\operatorname{pr}\left(Y_{1}=1 \mid D_{j}=0\right) \\
& =\Phi\left(\mathbf{x} \widehat{\boldsymbol{\beta}}-D_{j} \cdot \widehat{\boldsymbol{\beta}}_{D_{j}}+\widehat{\beta}_{D_{j}}\right)-\Phi\left(\mathbf{x} \widehat{\boldsymbol{\beta}}-D_{j} \cdot \widehat{\beta}_{D_{j}}\right)
\end{aligned}
$$

On the other hand, for a continuous variable, $X_{j}$, this effect would be obtained as:

$$
\partial \widehat{p} / \partial X_{j}=\left(\partial \mathbf{x} \widehat{\boldsymbol{\beta}} / \partial X_{j}\right) \phi(\mathbf{x} \widehat{\boldsymbol{\beta}})
$$

Given that $\mathbf{x} \boldsymbol{\beta}$ is linear with respect to $X_{j}$, then $\left(\partial \mathbf{x} \widehat{\boldsymbol{\beta}} / \partial X_{j}\right)$ $=\widehat{\beta}_{j}$, so $\partial \widehat{p} / \partial X_{j}=\widehat{\beta}_{j} \phi(\mathbf{x} \widehat{\boldsymbol{\beta}})$.

In both discrete and continuous cases, each marginal effect depends on all the estimated coefficients and all the regressors of the model, so their value is different for every observation. In order to obtain an aggregate measure, the average of these marginal effects should be calculated.

We have indicated above that the regressor Preoc_envir could be an endogenous binary variable, and we need to be sure of it in order to estimate the model adequately. Thus, if this regressor is endogenous, the probit estimates described above will be inconsistent, so we should estimate a bivariate probit model which, following Wooldridge (2002; p.477), can be written as follows:

$Y_{1}=1\left[\mathbf{x} \boldsymbol{\beta}+u_{1}>0\right]$
$Y_{2}=1\left[\mathbf{z} \gamma+u_{2}>0\right]$

where $Y_{1}$ and $Y_{2}$ are the binary variables previously named as Separate and Preoc envir, respectively; the regressor vector of Eq. (5) includes the endogenous $Y_{2}$ together with the exogenous $\mathbf{z}_{1}$, that is, $\mathbf{x}=\left(\begin{array}{ll}\mathbf{z}_{1} & Y_{2}\end{array}\right) ; \mathbf{z}$ is the regressor vector of (6); the parameter vectors in (5) and (6) are $\beta$ and $\gamma$, where $\beta^{\prime}=$ ( $\left.\delta \alpha_{1}\right)$; and finally, the error vector $\left(u_{1}, u_{2}\right)$ is distributed as bivariate normal with mean zero, both $u_{1}$ and $u_{2}$ have unit variance, and the correlation between them is $\rho$. In Eqs. (5) and (6), $1[\cdot]$ denotes an index, with value 1 if the condition in the brackets is satisfied and zero otherwise. Both conditions correspond to the respective latent equations $Y_{1}^{*}=\mathbf{z}_{1} \delta+\alpha_{1}$ $Y_{2}+u_{1}$ and $Y_{2}^{*}=\mathbf{z} \gamma+u_{2} \mathrm{Y}_{2}^{*}=\mathrm{z}_{2} \delta_{2}+\mathrm{v}_{2}$, being $Y_{1}^{*}$ and $Y_{2}^{*}$ two latent (non-observable) variables, which can be understood as the level of satisfaction of the option numbered with 1 values in $Y_{1}$ and $Y_{2}$, respectively. The variables included in vectors $\mathbf{x}$ and $\mathbf{z}$ of Eqs. (5)-(6) are shown in Table 5 .

Although our interest is focused on the probability of separating e-waste, if $Y_{2}$ is endogenous, we must estimate jointly (5) and (6). With this aim, we construct the log-likelihood by combining the probability of the four outcomes of $\left(Y_{1}, Y_{2}\right)$ : $P\left(Y_{1}=1 \mid Y_{2}=1, \mathbf{z}\right), P\left(Y_{1}=1 \mid Y_{2}=0, \mathbf{z}\right), P\left(Y_{1}=0 \mid Y_{2}=1\right.$, $\mathbf{z})$, and $P\left(Y_{1}=0 \mid Y_{2}=0, \mathbf{z}\right)^{6}$. Once we estimate (5)-(6) by ML, we test whether the correlation coefficient between the error terms of both equations, which we have called $\rho$, is, in fact, zero. The ML estimation of the bivariate model (5)(6) provides the estimate $\widehat{\rho}$. If we reject $H_{0}: \rho=0$, then we calculate the estimated probabilities of $Y_{1}=1$ from the estimates $\widehat{\delta}_{1}$ and $\widehat{\alpha}_{1}$ in Eq. (5) of the bivariate probit model. However, if we do not reject $H_{0}$, we can conclude that $Y_{2}$ is not an endogenous variable, so we must use the result of the estimation of the one-equation probit model $p=F(\mathbf{x} \beta)$.

Moreover, it should be noted that if the Preoc_envir variable were an endogenous binary regressor in Eq. (5) of the bivariate probit model, its marginal effect would be obtained directly from

\footnotetext{
${ }^{6}$ The full expression of the log-likelihood function can be found in Wooldridge (2002).
} 
Table 3 Selected explanatory variables

\begin{tabular}{|c|c|c|}
\hline \multicolumn{3}{|c|}{ Dependent variable: Separate $($ collect separately their e-waste $=1$, otherwise $=0$ ) } \\
\hline \multicolumn{3}{|c|}{ Set 1: personal and household characteristics } \\
\hline Factor & Variable & Description \\
\hline \multirow[t]{6}{*}{ Age } & Until20 & There are members who are until 20 years $($ yes $=1 ;$ no $=0$ ) \\
\hline & M20to30 & There are members who are from 20 to 30 years $(y e s=1 ;$ no $=0$ ) \\
\hline & M30to45 & $\begin{array}{l}\text { Household with members who are from } 30 \text { to } 45 \text { years } \\
(\text { yes }=1 ; \text { no }=0)\end{array}$ \\
\hline & M45to60 & There are members who are from 45 to 60 years $(y e s=1 ;$ no $=0$ ) \\
\hline & M60to 70 & There are members who are from 60 to 70 years $($ yes $=1 ;$ no $=0$ ) \\
\hline & More70 & There are members who are more than 70 years $($ yes $=1 ;$ no $=0$ ) \\
\hline Nmembers & Nmembers & Number of persons living in the household \\
\hline Married & Married & Marital status (married $=1$; otherwise $=0$ ) \\
\hline \multirow[t]{3}{*}{ Earnings } & Hearnings & Monthly earnings more than $2700 €($ yes $=1 ;$ no $=0)$ \\
\hline & Mearnings & Monthly earnings between $1101 €$ and $2700 €($ yes $=1 ;$ no $=0)$ \\
\hline & Learnings & Low earnings (monthly earnings less than $1101 €$, otherwise $=0$ ) \\
\hline Origin & Origin & The origin of the respondent (people born in Spain $=1 ; 0=$ otherwise) \\
\hline \multirow[t]{3}{*}{ Education } & Beatt & Basic educational attainment $($ yes $=1 ;$ no $=0$ ) \\
\hline & Meatt & Medium educational attainment $($ yes $=1 ;$ no $=0)$ \\
\hline & Heatt & High educational attainment $($ yes $=1 ;$ no $=0$ ) \\
\hline \multirow{4}{*}{$\begin{array}{l}\text { Relationship with } \\
\text { labour market }\end{array}$} & $O c c$ & Occupied $($ yes $=1 ;$ no $=0)$ \\
\hline & Unocc & Unoccupied $($ yes $=1 ;$ no $=0$ ) \\
\hline & Pensioner & Pensioner $($ yes $=1 ;$ no $=0$ ) \\
\hline & Student & Student $($ yes $=1 ;$ no $=0$ ) \\
\hline \multirow[t]{3}{*}{ City Size } & Large_city & $\begin{array}{l}\text { Provincial capitals and cities with } 100,000 \text { or more inhabitants } \\
(\text { yes }=1 ; \text { no }=0 \text { ) }\end{array}$ \\
\hline & Med_city & Cities from 20,000 to 100,000 inhabitants $($ yes $=1 ;$ no $=0$ ) \\
\hline & Small_city & Cities with less than 20,000 inhabitants $($ yes $=1 ;$ no $=0$ ) \\
\hline Gender & Gender & Gender of respondent $(\operatorname{man}=1 ;$ woman $=0)$ \\
\hline \multicolumn{3}{|c|}{ Set 2: Environmental attitudes } \\
\hline Factor & Variable & Description \\
\hline Preoc_envir & $\begin{array}{l}\text { Preoc } \\
\text { envir }\end{array}$ & Preoccupation with environmental issues (yes $=1 ;$ no $=0$ ) \\
\hline Awar_camp & $\begin{array}{l}\text { Awar } \\
\text { camp }\end{array}$ & $\begin{array}{l}\text { Knowledge of some environmental awareness campaign (yes }=1 \text {; no }= \\
\text { 0) }\end{array}$ \\
\hline Percep & Percep & $\begin{array}{l}\text { Perception of environmental troubles in his/her neighbourhood in the } \\
\text { last year }(\text { yes }=1 ; \text { no }=0 \text { ) }\end{array}$ \\
\hline
\end{tabular}

the bivariate estimation procedure that following the notation established above is $P\left(Y_{1}=1 \mid Y_{2}=1\right)-P\left(Y_{1}=1 \mid Y_{2}=0\right)$.

\section{Results}

\section{The estimation of the model}

The results of the bivariate probit estimation of Eqs. (5) and (6) are presented in Table 6 . Note that preliminary estimations allowed grouping some of the categories initially defined for Earnings (Hearnings with Mearnings), Relationship with labour market (Unocc with Pensioner and with Student), and City Size (Small_City with Med_City) reducing in this way the number of these kind of variables included in the final model.

Moreover, the results of the independence test between the error terms of Eqs. (5) and (6) are presented in Table 7.

The Wald test, which is distributed as $\chi_{1}^{2}$, has a value of 41.1827. The corresponding $p$ value (zero) implies that the null hypothesis $H_{0}: \rho=0$ is rejected, so both error terms are non-independent. This result allows us to conclude that we 
Table 4 Descriptive statistics of the variables

Set 1: personal and household characteristics

\begin{tabular}{|c|c|c|c|}
\hline Factor & Variable & Mean & Std. Dev. \\
\hline \multirow[t]{6}{*}{ Age } & Until20 & 0.344 & 0.475 \\
\hline & M20to30 & 0.253 & 0.434 \\
\hline & M30to45 & 0.417 & 0.493 \\
\hline & M45to60 & 0.355 & 0.478 \\
\hline & M60to 70 & 0.199 & 0.399 \\
\hline & More70 & 0.258 & 0.438 \\
\hline Nmembers & Nmembers & 2.596 & 1.234 \\
\hline Married & Married & 0.559 & 0.496 \\
\hline \multirow[t]{3}{*}{ Earnings } & Hearnings & 0.123 & 0.328 \\
\hline & Mearnings & 0.547 & 0.498 \\
\hline & Learnings & 0.330 & 0.470 \\
\hline Origin & Origin & 0.243 & 0.429 \\
\hline \multirow[t]{3}{*}{ Education } & Beatt & 0.574 & 0.494 \\
\hline & Meatt & 0.268 & 0.443 \\
\hline & Heatt & 0.157 & 0.364 \\
\hline \multirow[t]{3}{*}{ Relationship with labour market } & $O c c$ & 0.478 & 0.499 \\
\hline & Unocc & 0.058 & 0.233 \\
\hline & Pensioner & 0.253 & 0.435 \\
\hline \multirow[t]{3}{*}{ City Size } & Stungentcity & 0.038 & 0.488 \\
\hline & Med_city & 0.378 & 0.485 \\
\hline & Small_city & 0.243 & 0.429 \\
\hline Gender & Gender & 0.453 & 0.498 \\
\hline \multicolumn{4}{|l|}{ Set 2: environmental attitudes } \\
\hline Factor & Variable & & \\
\hline Preoc_envir & $\begin{array}{l}\text { Preoc } \\
\text { envir }\end{array}$ & 0.783 & 0.412 \\
\hline Awar_camp & Awar_camp & 0.615 & 0.487 \\
\hline Percep & Percep & 0.260 & 0.439 \\
\hline
\end{tabular}

must jointly estimate both Eqs. (5) and (6) as a bivariate probit model, in order to obtain consistent estimates.

If we observe the left side of Table 6, corresponding to Eq. (5), we can see the estimated parameters of factors that have a direct effect on the decision of households to deposit their ewaste at collection points. The coefficients of Preoc_envir and Origin are both positive, and they have the highest values. The estimated parameter of Nmembers is also positive, although its value is lower.

On the other hand, the estimated parameters corresponding to the variables Large_city, Learnings, and Occ are negative. Thus, respondents living in a large city have a probability of separating e-waste lower than that of respondents living in medium/small cities (control group). With respect to the Learnings variable, individuals with low incomes have a lower probability of recycling than those with medium or high
Table 5 Variables of the bivariate probit model (5)-(6)

\begin{tabular}{lll}
\hline Eq. (5) & & Eq. (6) \\
\hline Vector $\mathbf{x}$ & & Vector $\mathbf{z}$ \\
\hline $\mathbf{z}_{\mathbf{1}}$ & $\mathbf{Y}_{\mathbf{2}}$ & \\
\hline Learnings & Preoc_ & Learnings \\
Origin & & \\
Occ & & Beatt \\
Large_ciy & Large_ciy \\
Nmembers & Gender \\
M20to30 & Married \\
M45to60 & Origin \\
M60to70 & Heatt \\
More70 & Awar_ \\
& & camp \\
& & Percep \\
& M20to30 \\
& M45to60 \\
& M60to70 \\
& More70 \\
\hline
\end{tabular}

levels of income (control group). Analogously, working individuals have a smaller probability of separating e-waste, with respect to people in other labour situations (control group including student, unoccupied, or pensioner).

Finally, regarding the age interval dummies, we observe a negative sign for M20to30, indicating that the presence of people between 20 and 30 years old in the household reduces the probability of separating e-waste against the households where there are no people of this age range. However, the presence of people from the other age ranges considered increases this probability, as indicates the positive sign of their estimated coefficients.

Focusing now on the right side of Table 6, corresponding to Eq. (6) whose dependent variable is Preoc_envir, we can see the factors that have a direct effect on the probability of having environmental concern and also an indirect effect on the probability of separating e-waste, which is our main interest. In this way, it should be noted that there are four variables in Eq. (6) (Learnings, Large_city, Origin, and the interval age dummies) that also appeared in Eq. (5). In all of them, the sign of both direct and indirect effects is the same so the environmental concern of individuals reinforces the effect of these socio-economic variables on separating e-waste.

Furthermore, the variables married, gender, and basic and high education (Beatt and Heatt), as well as those that reflect the influence of knowledge of environmental issues (Awar_camp and Percep), have only indirect effects. In this way, the sign of the estimated coefficients of these variables shows how they contribute to sorting e-waste intentions through their environmental concern. 
As can be seen in Table 6, women and married people show a higher tendency to separate their e-waste than men and single people, respectively.

As we have just seen, the estimated coefficient of every regressor allows us to know the direction of the change in the probability when a regressor changes. However, it is possible that the effect of the age of members of the household on the probability differs depending on the level of earnings, the labour situation, and so on. In order to take this into account, we have defined some interaction variables (the product of the dummies of two different factors) to be included as regressors in Eq. (5). Specifically, interactions between the age interval of members in the household and the city size provide significant results. The results of the estimation of this bivariate probit model with interactions are shown in Table 8.

As we can see in Table 8, the Wald test indicates that the errors of Eqs. (5) and (6) are not independent, so the bivariate probit model procedure is adequate.

Table 8 shows that parameters of all interaction terms $\left(\delta_{11}\right.$, $\delta_{12}$, and $\left.\delta_{13}\right)$ are significant at $5 \%$ and $10 \%$, except that of Large_M20to30 $\left(\delta_{10}\right)$. This non-significance means that the city size (large or small) does not affect the change in the probability of separating e-waste between households with individuals from 20 to 30 years old and those without them. Analogously, to have or not to have individuals in this age range has no influence on the effect of city size on the probability of separating. This result is different for the other age ranges, as we can derive from the statistical significance of $\delta_{11}$, $\delta_{12}$, and $\delta_{13}$.

Table 6 Bivariate probit estimation results

\begin{tabular}{|c|c|c|c|}
\hline \multicolumn{2}{|c|}{$\begin{array}{l}\text { Eq. (1) } \\
\text { Dependent variable: Separate }\end{array}$} & \multicolumn{2}{|c|}{$\begin{array}{l}\text { Eq. (2) } \\
\text { Dependent variable: Preoc_envir }\end{array}$} \\
\hline Regressors $\left(\mathrm{z}_{1}\right)$ & Coefficient value & Regressors (z) & Coefficient value \\
\hline Const & $-0.7972 * * *$ & Const & $0.3897 * * *$ \\
\hline Preoc_envir & $0.8679 * * *$ & Learnings & $-0.0673 * * *$ \\
\hline Learnings & $-0.2140 * * *$ & Beatt & $-0.1866 * * *$ \\
\hline Origin & $0.5081 * * *$ & Large_ciy & $0.0780^{* * *}$ \\
\hline$O c c$ & $-0.0439 *$ & Gender & $-0.1403 * * *$ \\
\hline Large_ciy & $-0.0439 * *$ & Married & $0.1386^{* * *}$ \\
\hline Nmembers & $0.0522 * * *$ & Origin & $0.1477 * * *$ \\
\hline M20to30 & $-0.0801 * * *$ & Heatt & $0.1055 * * *$ \\
\hline M45to60 & $0.1991 * * *$ & Awar_camp & $0.5051 * * *$ \\
\hline M60to70 & $0.1500 * * *$ & Percep & $0.4034 * * *$ \\
\hline \multirow[t]{4}{*}{ More70 } & $0.1075 * * *$ & M20to30 & $-0.0446^{*}$ \\
\hline & & M45to60 & $0.0833 * * *$ \\
\hline & & M60to70 & $0.0648 * *$ \\
\hline & & More70 & $-0.1866 * * *$ \\
\hline
\end{tabular}

$*, * *$, and $* * *$ indicate statistical significance at the $10 \%, 5 \%$, and $1 \%$ level, respectively
Regarding the other explanatory factors considered in the model, we see that $O c c$ is only significant at $10 \%$, while the others are significant at $1 \%$ and $5 \%$. The sign of the coefficients in Table 8 holds with respect to those of the previous estimation without interactions (Table 6). The estimated magnitude for parameters of variables not affected by the interaction is also held.

\section{The marginal effects}

The average marginal effects corresponding to the bivariate probit model without interactions (see Table 6) are presented in Table 9. It is noteworthy that Preoc_envir has the largest value among the marginal effects $(0.3381)$, followed by Origin (0.1789).

Then, in the estimation of Eq. (5), four interaction terms were introduced: (Large x M20to30), (Large x M45to60), (Large x M60to70), and (Large x More70). As we can see in Table 10, from these four interaction terms, it is possible to define sixteen categories based on age range of household members and city size.

In Tables 11, 12, and 13, the marginal effects for the model with interaction variables are presented. Note that the calculation of those corresponding to regressors with interactions is quite different from that described in (3). Details about the way of obtaining them are in Appendix 1. Specifically, Table 11 shows the average marginal effects of the city size for every age range and Table 12 the average marginal effects of the age intervals for large cities and for small cities.

Focusing on Table 11, the first row shows the change in the probability of separating e-waste between large and small cities, when there are household members in a given age range. Thus, if the household includes members belonging to the age range 20-30 years old, the probability of separating e-waste in a large city decreases by 0.022 in comparison with a medium to small city. There are almost no differences in probability between large and small cities if there are members in the age intervals $45-60$ years old $(0.0057)$ and more than 70 years old (a change of 0.0083 ). When there are individuals between 60 and 70 years old, the probability slightly increases (a change of 0.018 ).

The second row of Table 11 provides the changes in probability between large and small cities when there are no individuals in a given age interval. We see that in large cities, this probability is lower than that in small cities, whatever the age interval considered.

In the model without interactions, the probability of separating e-waste in a large city was lower by 0.014 than in a small city, as we can see in Table 9. Now, in Table 11, we can see absolute values lower and higher than 0.014 , being some of them positive.

The two rows of Table 12 give the change in probability when we compare the households with and without members 
Table 7 Test of independence of the two equations in the bivariate model

\begin{tabular}{ll}
\hline$\widehat{\rho}$ & -0.3509694 \\
\hline Hypotheses & $H_{0}: \rho=0$ \\
Wald test & $H_{A}: \rho \neq 0$ \\
$\quad$ value & 41.1827 \\
Distribution & \\
$p$ value & $\chi_{1}^{2}$ \\
\hline
\end{tabular}

from a given age range. As we can see in Table 9, without interaction between age and city size, the effects were $0.0263,0.0642,0.0478$, and 0.0345 for the four intervals, respectively. Now, with interactions, the sign is held, but the absolute value is larger when the household is in a large city, indicating that the effect of the age of members in the household on the probability of recycling e-waste depends on the city size.

It should be noted that having individuals from 20 to 30 years old in the household (i.e. those who consume most electrical and electronic devices) reduces the probability of separating e-waste in both large and small cities. Another noteworthy result is that the largest increase in the probability of separating e-waste occurs in those households in large cities where some of its members are in the age ranges 45 to 60 and 60 to 70 . Specifically, this probability increases by 0.083 and 0.073 with respect to households in large cities where there is no member in these age ranges. In small cities, these increases in the probability of separating e-waste in these two age ranges are lower (0.052 and 0.032, respectively).

Hence, including interaction terms can provide more reliable estimations for the effects of the explanatory variables. To complete this analysis, Table 13 shows the average marginal effects corresponding to the regressors included in the estimated model with interactions (Table 8), but not implied in the interactions. The results do not change with respect to Table 9, as expected.

\section{Discussion}

In this study, we have observed that there are two relevant factors in explaining the decision of households to collect separately their e-waste for proper disposal: the preoccupation with environmental issues and the origin of the people.

Regarding the first variable (Preoc_envir), the econometric estimation reveals that it positively affects the attitudes of households towards e-waste separation and collection. It should be noted that this result is in line with the bulk of the prior research concluding that a pro-environmental concern encourages households to manage their e-waste appropriately
Table 8 Estimation of a bivariate probit model with interaction variables

\begin{tabular}{|c|c|c|c|c|c|}
\hline \multicolumn{3}{|c|}{ Eq. (1). Dependent variable: Separate } & \multicolumn{3}{|c|}{ Eq. (2). Dependent variable: Preoc_envir } \\
\hline $\begin{array}{l}\text { Coeficient } \\
\text { name }\end{array}$ & Regressors $\left(\mathrm{z}_{1}\right)$ & $\begin{array}{l}\text { Coefficient } \\
\text { value }\end{array}$ & $\begin{array}{l}\text { Coeficient } \\
\text { name }\end{array}$ & Regressors (z) & $\begin{array}{l}\text { Coefficient } \\
\text { value }\end{array}$ \\
\hline$\alpha_{1}$ & Preoc_envir & $0.8686^{* * *}$ & $\gamma_{0}$ & Const & $0.3895 * * *$ \\
\hline$\delta_{0}$ & Const & $-0.7725^{* * *}$ & $\gamma_{1}$ & Learnings & $-0.0674 * * *$ \\
\hline$\delta_{1}$ & Learnings & $-0.2102 * * *$ & $\gamma_{2}$ & Beatt & $-0.1863^{* * *}$ \\
\hline$\delta_{2}$ & Origin & $0.5078 * * *$ & $\gamma_{3}$ & Heatt & $0.1061 * * *$ \\
\hline$\delta_{3}$ & $O c c$ & $-0.0415^{*}$ & $\gamma_{4}$ & Large_ciy & $0.0776 * * *$ \\
\hline$\delta_{4}$ & Large_ciy & $-0.1173 * * *$ & $\gamma_{5}$ & Gender & -0.1403 *** \\
\hline$\delta_{5}$ & Nmembers & $0.0524 * * *$ & $\gamma_{6}$ & Married & $0.1383^{* * *}$ \\
\hline$\delta_{6}$ & M20to30 & $-0.0689 * *$ & $\gamma_{7}$ & Origin & $0.1476^{* * *}$ \\
\hline$\delta_{7}$ & M45to60 & $0.1633^{* * *}$ & $\gamma_{8}$ & Awar_camp & $0.5049 * * *$ \\
\hline$\delta_{8}$ & M60to70 & $0.1029 * * *$ & $\gamma_{9}$ & Percep & $0.4037 * * *$ \\
\hline$\delta_{9}$ & More70 & $0.0724 * *$ & $\gamma_{10}$ & M20to30 & $-0.0447^{*}$ \\
\hline$\delta_{10}$ & $\begin{array}{l}\text { Large } \\
\quad \text { M20to30 }\end{array}$ & -0.0306 & $\gamma_{11}$ & M45to60 & $0.0838^{* * *}$ \\
\hline$\delta_{11}$ & $\begin{array}{l}\text { Large } \\
\quad \text { M45to60 }\end{array}$ & $0.0951 * *$ & $\gamma_{12}$ & M60to 70 & $0.0656^{* *}$ \\
\hline$\delta_{12}$ & $\begin{array}{l}\text { Large } \\
\quad \text { M60to } 70\end{array}$ & $0.1293 * *$ & $\gamma_{13}$ & More70 & $-0.1861 * * *$ \\
\hline$\delta_{13}$ & Large_More70 & $0.0966^{* *}$ & & & \\
\hline \multicolumn{6}{|c|}{ Wald test $\left(\right.$ for $\left.H_{0}: \rho=0\right)=41.248, p$ value $=0.0$} \\
\hline
\end{tabular}

$*$, **, and $* * *$ indicate statistical significance at the $10 \%, 5 \%$, and $1 \%$ level, respectively 
Table 9 Average marginal effects of bivariate probit model without interaction variables
Eq. (1).

Dependent variable: Separate

\begin{tabular}{ll}
\hline Regressors $\left(\mathrm{z}_{1}\right)$ & Coefficient value \\
\hline Preoc_envir & $0.3381 * * *$ \\
Learnings & $-0.0712 * * *$ \\
Origin & $0.1789 * * *$ \\
Occ & $-0.0142 *$ \\
Large_ciy & $-0.0143 * *$ \\
Nmembers & $0.0169 * * *$ \\
M20to30 & $-0.0263 * * *$ \\
M45to60 & $0.0642 * * *$ \\
M60to70 & $0.0478 * * *$ \\
More70 & $0.0345 * * *$ \\
\hline
\end{tabular}

$*, * *$, and $* * *$ indicate statistical significance at the $10 \%, 5 \%$, and $1 \%$ level, respectively

(e.g. Arbués and Villanúa 2016; Keuschnigg and Kratz 2018). Therefore, the relevance of environmental concern in the intention to properly disposal e-waste points to the crucial role that environmental education must play in promoting proper e-waste management in the households. It is noteworthy that this result supports those of Pérez-Belis et al. (2015b) who concluded that in order to avoid unsorted disposal of electric and electronic toys, it was necessary to train and provide information to consumers about how to manage this kind of ewaste properly.

Thus, it will be very important to reinforce the environmental awareness programmes related to SDGs promotion campaigns, periodically designing campaigns of short duration aimed at different education levels (from preschool to postsecondary). In addition, emphasis should be placed on introducing into the contents of science subjects (for example, in the Spanish secondary education level curriculum, there is a subject labelled scientific culture) several topics that reinforce concern about the environmental problems of hazardous waste in general and e-waste in particular. In summary, environmental education should be a lifelong learning process to promote a proactive environmental citizenship. In this context, the collaboration between environmental authorities (national, regional or local), the educational system, producers and companies (as remark Pérez-Belis et al. 2015b), communication media, and even the so-called influencers, who have a great capacity to impact their followers on social networks, should be enhanced to ensure engagement of households in e-waste separate collection.

Focusing on the second variable (Origin), the positive sign of its estimated parameter indicates, as well as Lakhan (2015) and Zen et al. (2014), that there are discrepancies in attitudes of households towards their e-waste management depending on the origin of their members. Specifically, this positive sign means that individuals born in Spain tend to separate their ewaste more often than those born in other countries. Furthermore, this result suggests, in line with Pearson et al. (2012) and Perry and Williams (2007), that the practice of separating e-waste is influenced by the perception of the problems related to e-waste in their origin countries and by their consumption patterns (i.e. people from developing countries and some regions of Eastern Europe tend to practise "informal" recycling and reuse). It will therefore be important to spread measures in different languages since many of the people born out of Spain who do not come from Latin America are often not fluent in the Spanish language. Additionally, given the different levels of environmental concern among nations around the world, the migrant social networks (diaspora organizations, nongovernmental organizations, religious and cultural organizations, and so on) should play an important role in getting the message about the importance of recycling across to these communities.

A further factor considered in the study with a positive estimated parameter is the household size (Nmembers). Note that this result is consistent with many previous empirical works such as that of Martinho et al. (2017), Pérez-Belis et al. (2015b), or Sidique et al. (2010), among others. Further, the value of this estimated parameter is quite low, so the probability of households properly managing the ewaste increases slightly with their size. Its shows consistency with Sidique et al. (2010) and Lo and Liu (2018) which indicate that the effects of household size on proper waste management are limited.

On the other hand, we can also observe in the study that Large city, Learnings, and Occ have negative estimated coefficients. As we have indicated above, in the case of
Table 10 Name of the groups defined through interaction variable

\begin{tabular}{|c|c|c|c|c|c|c|c|c|}
\hline & \multicolumn{2}{|c|}{$\begin{array}{l}\text { Age interval A: } \\
20-30 \text { years }\end{array}$} & \multicolumn{2}{|c|}{$\begin{array}{l}\text { Age interval B: } \\
45-60 \text { years }\end{array}$} & \multicolumn{2}{|c|}{$\begin{array}{l}\text { Age interval C: } \\
60-70 \text { years }\end{array}$} & \multicolumn{2}{|c|}{$\begin{array}{l}\text { Age interval D: } \\
\text { more than } 70\end{array}$} \\
\hline & With & Without & With & Without & With & Without & With & Without \\
\hline Large & $\frac{\mathrm{GL1}}{\mathrm{A}}$ & GL0_A & $\underset{\mathrm{B}}{\mathrm{GL1}}$ & GLO_B & $\underset{\mathrm{CL}}{\mathrm{G}}$ & GLO_C & $\underset{\mathrm{CL}}{\mathrm{G}}$ & GL0_D \\
\hline Small & GS1_A & GS0_A & GS1_B & GS0_B & GS1_C & GS0_C & GS1_D & GS0_D \\
\hline
\end{tabular}


Table 11 Average marginal effects of city size

\begin{tabular}{lllll}
\hline & $\mathbf{2 0 - 3 0}$ & $\mathbf{4 5 - 6 0}$ & $\mathbf{6 0 - 7 0}$ & More than 70 \\
\hline $\operatorname{Pr}($ GL1)-Pr(GS1) & $-0.0221737 * * *$ & 0.005785 & 0.0184338 & 0.0083113 \\
$\operatorname{Pr}($ GL0)-Pr(GS0) & $-0.0116819 * * *$ & $-0.0256195 * * *$ & $-0.022623 * * *$ & $-0.0226978 * * *$ \\
\hline
\end{tabular}

$*, * *$, and $* * *$ indicate statistical significance at the $10 \%, 5 \%$, and $1 \%$ level, respectively

Large_city, this negative relationship means that respondents living in a large city have a probability of separating e-waste lower than that of respondents living in a medium or small city. Although several prior studies find a positive sign for this variable (e.g. Aprile and Fiorillo 2019; Dwivedy and Mittal 2013), this result supports the findings that distance to collection points is a barrier to recycling obtained by Hage et al. (2009) and Sorkun (2018), among others. It is noteworthy that in Spain, the collection points to deposit e-waste are usually on industrial estates located outside the city, so that separate disposal of e-waste implies storage, time, and transport costs for individuals. The larger the city, and the greater the distance to the collection point, these costs grow, and recycling efforts decrease.

Concerning the Learnings variable, its negative estimated coefficient implies that the individuals with low incomes have a lower probability of properly disposing their e-waste than those with higher levels of income. This negative relationship is similar to that observed in many preceding works, such as those of Song et al. (2012) and Zen et al. (2014), and may be related to the fact that informal recycling sometimes can be a source of additional income for these households. Furthermore, this result is in line with the positive sign of the estimated coefficient of the variable Origin. In Spain, according to INE (2020), the average income per person of foreign residents is lower than that of the Spanish nationals (a $47.78 \%$ below in the case of non- EU foreigners and $35.44 \%$ below in the case of UE foreigners).

On other hand, the negative estimated coefficient of Occ indicates that working individuals have a smaller probability to dispose of their e-waste correctly, than people who are in other labour situations. This is a piece of evidence that few prior empirical works have found (Sidique et al. 2010; Yakob et al. 2020). However, this negative relationship is consistent with the idea implicit in the estimated coefficient for Large_city, which pointed out that time availability is a relevant factor in recycling activities. Thus, working people are probably to have more time constraints than unemployed, students, or retired people to conduct recycling activities on a regular basis and even for disposing their e-waste at collection points (e.g. incompatibility between their working hours and the opening hours of the collection points).

Regarding age, the relations estimated between age intervals and recycling behaviour are in parallel with previous studies (Sidique et al. 2010; Sorkun 2018). Specifically, our study shows that the presence of people between 20 and 30 years old in the household reduces the probability of properly managing their e-waste against the households where there are no people of this age range. However, the presence of people from the other age ranges considered increases this probability, as indicates the positive sign of their estimated coefficients. This result is consistent with the fact that households with young members tend to have more electronic devices (smartphones, tablets, laptops, etc.) than households without them. Furthermore, as remark Martinho et al. (2017), it is common for young people to keep their old devices as an alternative in case of breakdown or loss of the new one. Sometimes, the lack of knowledge between young people about where to deliver the old devices (Martinho et al. 2017) and the inconvenience of having to go to a specific location are other factors influencing this result.

At this point, it should be noted that the results obtained from the interaction between the age of the individuals and the size of the city show the need to focus greater attention on people between 20 and 30 years old living in large Spanish cities. This calls attention to the importance of designing campaigns adapted to the digital communication and of using the trending social networks among young people (e.g. YouTube, Twitch, TikTok, or Instagram) as priority channels for spreading messages about the importance of properly managing ewaste. It is noteworthy that, as Pérez-Belis et al. (2015b) show, the way in which campaigns convey the environmental information is key to their success.

Similar to previous empirical works, such as Aprile and Fiorillo (2019), De Feo and De Gisi (2010), and Pearson et al. (2012), our estimation finds that women and married
Table 12 Average marginal effects of age ranges

\begin{tabular}{|c|c|c|c|c|}
\hline & $20-30$ & $45-60$ & $60-70$ & More than 70 \\
\hline $\operatorname{Pr}($ GL1)-Pr(GL0) & $-0.032939 * * *$ & $0.0838692 * * *$ & $0.0738832 * * *$ & $0.0541919 * * *$ \\
\hline Pr(GS1)-Pr(GS0) & $-0.0224472 * *$ & $0.0524647 * * *$ & $0.0328264 * * *$ & $0.0231828 * *$ \\
\hline
\end{tabular}

$*, * *$, and $* * *$ indicate statistical significance at the $10 \%, 5 \%$, and $1 \%$ level, respectively 
Table 13 Average marginal effects with interaction variables

\begin{tabular}{ll} 
Eq. (1). Dependent variable: Separate \\
\hline Regressors $\left(\mathrm{z}_{1}\right)$ & Coefficient value \\
\hline Preoc_envir & $0.3381 * * *$ \\
Learnings & $-0.0698^{* * *}$ \\
Origin & $0.1787^{* * *}$ \\
Occ & $-0.0135^{*}$ \\
Nmembers & $0.0170^{* * *}$ \\
\hline
\end{tabular}

$*, * *$, and $* * *$ indicate statistical significance at the $10 \%, 5 \%$, and $1 \%$ level, respectively

people are more prone to properly manage their e-waste than men and single people, respectively. It is noteworthy that this positive relationship between these variables and recycling behaviour may be explained by the fact that in Spain, according to INE (2011), women dedicate more time than men to both household tasks (such as sorting waste) and volunteer activities (including pro-environmental activities). Regarding the effect of the educational variables considered, the sign of the coefficients (negative for basic education and positive for high education) indicates that the higher the level of education, the more likely for the households to separate their ewaste. This finding corroborates the importance of education to commit people to adopting proactive environmental attitudes, such as proper management of their e-waste (PérezBelis et al. 2015b). This positive correlation between high education and recycling behaviour is consistent with most previous papers, as those of Aprile and Fiorillo (2019), Liu et al. (2020), Sidique et al. (2010), and Sorkun (2018), among others.

Finally, note that most of the results obtained in our study indicate that the time and knowledge of how to access the collection points are a major impediment to adequately separate e-waste. For this reason, it is necessary to implement measures aimed at improving the collection point networks (i.e. extending their opening hours, installing e-waste drop-off points in shopping centres and retail stores, or increasing the frequency and the number of mobile e-waste collection points) and the information about where and how households can dispose of their ewaste to be recycled.

\section{Concluding remarks}

The purpose of this paper is to analyse the factors influencing the intention of Spanish households to separate their e-waste for proper disposal. Our analysis shows that environmental concern should be considered as an endogenous binary variable, rather than exogenous, when analysing the determinants of behaviour towards separate collection of e-waste. This is a very relevant result that has clear implications for policymakers, since it indicates that to properly analyse the environmental behaviours of households such as e-waste separate collection, it is necessary to estimate a two-equation binary model, rather than the commonly used one-equation probit, because the latter obtains inconsistent estimates.

Moreover, another advantage of the two-equation model estimation procedure carried out in this paper is that it allows us to observe both direct and indirect effects of the regressors on the probability of separating e-waste. It is important to remark that the preoccupation with environmental issues behaves as an endogenous factor, being a function of several exogenous regressors, which may affect the probability of separating e-waste in an indirect way. This is also very important information for policymakers seeking to select the priority groups for an e-waste recycling programme.

Thus, the results obtained from the two-equation binary model allow us to segment individuals in order to define adequately which users should be the focus of a specific campaign to encourage e-waste separation and collection because it allows policymakers to identify which factors directly and indirectly influence household behaviour. It is a proven fact that adopting measures tailored to the characteristics of the individual increases the effectiveness of e-waste management for two reasons: first, it will improve the level of knowledge of the environmental problems arising from the hazardous components of e-waste, and secondly, it will reinforce the conservation message embodied in these measures.

Specifically, the results obtained in the study point to two main ways of intervention: reinforcing environmental education (both from a formal and an informal approach) and reducing the costs of properly disposing of e-waste by improving the collection point networks.

Finally, we should note that this study has some limitations that open up interesting paths for future research. First, the empirical analysis has been carried out using cross-sectional data. Because past situations can influence future decisions, a next step of study could be to analyse the relationships between household e-waste attitudes and its drivers using time series or panel data. This kind of data can allow us to observe the evolution of the variables over time and to use other analytical procedures (e.g. unit root test, cointegration test) in line with other research developed in near areas such as $\mathrm{CO}_{2}$ emissions, as we can see in Lin and $\mathrm{Xu}$ (2020) and $\mathrm{Xu}$ and Lin (2018). Secondly, the study is focused on urban households from Spain. For this reason, an interesting next step of analysis would be to replicate our methodological purpose to other countries with different socio-economic and cultural characteristics. In this way, future research should also cover household e-waste separation and disposal in rural areas. 


\section{Appendix}

For the case of households with/without members from 20 to 30 years old, the interaction variables allows to distinguish the following four categories:

- Group GL1_A: Household is in a large city with some members from 20 to 30 (Large_city $=1$, M20to $30=1$, and Large M20to30=1).

- Group GS1_A: Household is in a small city with some members from 20 to 30 (Large_city $=0$, M20to30 $=1$, and Large $M 20$ to $30=0$ ).

- Group GL0_A: Household is in a large city without some members from 20 to 30 (Large city $=1$, M20to30 $=0$, and Large_M20to30=0).

- Group GS0_A: Household is in a small city without some members from 20 to 30 (Large city $=0$, M20to30 $=0$, and Large_M20to30 $=0$ ).

If we want to obtain the average marginal effect of the city size in households with members between 20 and 30 years of age (age interval A) we must calculate:

$\operatorname{Pr}\left(\mathrm{GL} 1 \_\mathrm{A}\right)-\operatorname{Pr}\left(\mathrm{GS} 1 \_\mathrm{A}\right)$ $=\Phi(\mathbf{x} \boldsymbol{\beta} \mid$ Large_city $=1$, M20to $30=1$, Large_M20to30 $=1)-$ $\Phi(\mathbf{x} \beta \mid$ Large_city $=0$, M20to30 $=1$, Large $M 20$ to $30=0)$

However, if there is nobody in this age interval, the marginal effect will be:

$\operatorname{Pr}\left(G L 0 \_A\right)-\operatorname{Pr}\left(G S 0 \_A\right)$

$=\Phi(\mathbf{x} \boldsymbol{\beta} \mid$ Large_city $=1$, M20to30 $=0$, Large_M20to30 $=0)-$

$\Phi(\mathbf{x} \boldsymbol{\beta} \mid$ Large_city $=0$, M20to30 $=0$, Large_M20to30 $=0)$

Now we want to obtain the marginal effect of having people of interval A in the household against not having members of this age. In large cities, this partial effect will be calculated as:

$\operatorname{Pr}\left(G L 1 \_A\right)-\operatorname{Pr}\left(G L 0 \_A\right)$

$=\Phi\left(\mathbf{x} \boldsymbol{\beta} \mid\right.$ Large_city $=1$, M20to $30=1$, Large $\_$M20to $\left.30=1\right)-$

$\Phi(\mathbf{x} \boldsymbol{\beta} \mid$ Large_city $=1$, M20to30 $=0$, Large_M20to30 $=0)$

However, in a small city this effect is given by:

$\operatorname{Pr}(G S 1 A)-\operatorname{Pr}(G S 0 A)$

$=\Phi(\mathbf{x} \boldsymbol{\beta} \mid$ Large_city $=0$, M20to30 $=1$, Large_M20to30 $=1)-$

$\Phi(\mathbf{x} \beta \mid$ Large_city $=0$, M20to30 $=0$, Large $M 20$ to $30=0)$

Analogously, we obtain the marginal effects corresponding to the other interval age (B, C, and D), in order to obtain the values of the cells in Tables 7 and 8 .

Author contribution Fernando Arbués and Inmacualda Villanúa contributed equally to the study conception and design. Fernando Arbués and Inmaculada Villanúa read and approved the final manuscript.

Funding Open Access funding provided thanks to the CRUE-CSIC agreement with Springer Nature. This work was supported by the Spanish Ministry of Economy and Competitiveness and the European
Regional Development Fund [grant number ECO2016-75237-R], the National Institute for Agricultural and Food Research and Technology (INIA) [grant number RTA-2017-00082-00-00], and the Government of Aragon (Spain) and the European Social Fund [Public Economics Research Group and Growth Demand and Natural Resources Research Group]

Data Availability The datasets analysed during the current study are available in the INE (2010) Survey on Households and the Environment 2008 microdata dataset (ftp://www.ine.es/temas/hogmed/ datos hogmed.zip).

\section{Declarations}

Ethics approval and consent to participate Not applicable

Consent for publication Not applicable

Competing interests The authors declare no competing interests.

Open Access This article is licensed under a Creative Commons Attribution 4.0 International License, which permits use, sharing, adaptation, distribution and reproduction in any medium or format, as long as you give appropriate credit to the original author(s) and the source, provide a link to the Creative Commons licence, and indicate if changes were made. The images or other third party material in this article are included in the article's Creative Commons licence, unless indicated otherwise in a credit line to the material. If material is not included in the article's Creative Commons licence and your intended use is not permitted by statutory regulation or exceeds the permitted use, you will need to obtain permission directly from the copyright holder. To view a copy of this licence, visit http://creativecommons.org/licenses/by/4.0/.

\section{References}

Afroz R, Rahman A, Masud M, Akhtar R (2017) The knowledge, awareness, attitude and motivational analysis of plastic waste and household perspective in Malaysia. Environ Sci Pollut Res 24:2304-2315. https://doi.org/10.1007/s11356-016-7942-0

Aprile MC, Fiorillo D (2019) Intrinsic incentives in household waste recycling: the case of Italy in the year 1998. J Clean Prod 227:98110. https://doi.org/10.1016/j.jclepro.2019.04.184

Arbués F, Villanúa I (2016) Determinants of behavior toward selective collection of batteries in Spain. A bivariate probit model. Resour Conserv Recycl 106:1-8. https://doi.org/10.1016/j.resconrec.2015. 11.004

Barr S, Gilg AW, Ford NJ (2001) Differences between household waste reduction, reuse and recycling behaviour: a study of reported behaviours, intentions and explanatory variables. Environ Waste Manag 4: 69-82

Budak F, Oguz B (2008) Household participation in recycling programs: a case study from Turkey. J Environ Biol 29:923-927

Byrne S, O'Regan B (2014) Attitudes towards recycling behaviours in the Limerick, Ireland region. Resour Conserv Recycl 102:94-100. https://doi.org/10.1016/j.resconrec.2014.03.001

Cai K, Song Q, Peng S, Yuan W, Liang Y, Li J (2020) Uncovering residents' behaviors, attitudes, and WTP for recycling e-waste: a case study of Zhuhai city, China. Environ Sci Pollut Res 27:23862399. https://doi.org/10.1007/s11356-019-06917-x 
Crociata A, Agovino M, Sacco PL (2015) Recycling waste: does culture matter? J Behav Exp Econ 55:40-47. https://doi.org/10.1016/j. socec.2015.01.005

Czajkowski M, Hanley N, Nyborg K (2017) Social norms, morals and self-interest as determinants of pro-environment behaviours: the case of household recycling. Environ Resour Econ 66:647-670. https://doi.org/10.1007/s10640-015-9964-3

Darby L, Obara L (2005) Household recycling behaviour and attitudes towards the disposal of small electrical and electronic equipment. Resour Conserv Recycl 44:17-35. https://doi.org/10.1016/j. resconrec.2004.09.002

De Feo G, De Gisi S (2010) Domestic separation and collection of municipal solid waste: opinion and awareness of citizens and workers. Sustainability 2:1297-1326. https://doi.org/10.3390/su2051297

Do Valle PO, Reis E, Menezes J, Rebelo E (2004) Behavioral determinants of household recycling participation. The Portuguese Case. Environ Behav 36:505-540. https://doi.org/10.1177/ 0013916503260892

Dwivedy M, Mittal RK (2013) Willingness of residents to participate in ewaste recycling in India. Environ Dev 6:48-68. https://doi.org/10. 1016/j.envdev.2013.03.001

European Commission (2019) The EU environmental implementation review 2019 country report - SPAIN. European Union, Brussels

European Commission (2020). Waste electrical and electronic equipment (WEEE). http://ec.europa.eu/environment/waste/weee/index_en. $\mathrm{htm}$. Accessed February 16, 2021

European Union (2012) Directive 2012/19/EU of the European Parliament and of the Council on waste electrical and electronic equipment (WEEE). https://eur-lex.europa.eu/legal-content/EN/ TXT/PDF/?uri=CELEX:32012L0019\&from=EN. Accessed 28 March 2021

EUROSTAT (2021a) Recycling rate of e-waste (CEI WM050). https:// appsso.eurostat.ec.europa.eu/nui/show.do?dataset $=$ cei wm050\&lang=en. Accessed 1 April 2021

EUROSTAT (2021b) Waste electrical and electronic equipment (WEEE) by waste management operations (env_waselee). http://appsso. eurostat.ec.europa.eu/nui/show.do?lang=en\&dataset=env_waselee Accessed 1 April 2021

Ferrara I, Missios P (2005) Recycling and waste diversion effectiveness: evidence from Canada. Environ Resour Econ 30:221-238. https:// doi.org/10.1007/s10640-004-1518-Z

Forti V, Baldé CP, Kuehr R, Bel G (2020). The global e-waste monitor 2020: quantities, flows and the circular economy potential. United Nations University (UNU), United Nations Institute for Training and Research (UNITAR) - co-hosted SCYCLE Programme, International Telecommunication Union (ITU) and International Solid Waste Association (ISWA), Bonn/Geneva/Rotterdam

Hage O, Söderholm P, Berglund C (2009) Norms and economic motivation in household recycling: evidence from Sweden. Resour Conserv Recycl 53:155-165. https://doi.org/10.1016/j.resconrec. 2008.11.003

Hansmann R, Bernasconi P, Smieszek T, Loukopoulos P, Scholz RW (2006) Justifications and self-organization as determinants of recycling behavior: The case of used batteries. Resour Conserv and Recycl 47:133-159. https://doi.org/10.1016/j.resconrec.2005. 10.006

Hornik J, Cherian J, Madansky M, Narayana C (1995) Determinants of recycling behavior: a synthesis of research results. J Socio-Econ 24: 105-127. https://doi.org/10.1016/1053-5357(95)90032-2

INE (2009) Survey on households and the environment 2008. Methodological Note. https://www.ine.es/en/metodologia/t25/ t2530500_en.pdf. Accessed 28 March 2021

INE (2010) Survey on households and the environment 2008. Microdata. [dataset] ftp://www.ine.es/temas/hogmed/datos_hogmed.zip

INE (2011) Time use survey. Results. https:/www.ine.es/dyngs/ INEbase/en/operacion.htm?c=Estadistica_C\&cid=
$1254736176815 \&$ menu $=$ resultados $\& \mathrm{idp}=1254735976608$. Accessed 28 March 2021

INE (2020) Life conditions survey. Year 2019. Retrieved from: https:// www.ine.es/dyngs/INEbase/en/operacion.htm?c=Estadistica $\mathrm{C} \& \mathrm{cid}=1254736176807 \&$ menu $=u$ ltiDatos $\& \mathrm{idp}=1254735976608$. Accessed February 142021

Islam MT, Dias P, Huda N (2020) Waste mobile phones: a survey and analysis of the awareness, consumption and disposal behavior of consumers in Australia. J Environ Manag 275:111111. https://doi. org/10.1016/j.jenvman.2020.111111

Jafari A, Heydari J, Keramati A (2017) Factors affecting incentive dependency of residents to participate in e-waste recycling: a case study on adoption of e-waste reverse supply chain in Iran. Environ Dev Sustain 19:325-338. https://doi.org/10.1007/s10668-015-9737-8

Keuschnigg M, Kratz F (2018) Thou shalt recycle: how social norms of environmental protection narrow the scope of the low-cost hypothesis. Environ Behav 50:1059-1091. https://doi.org/10.1177/ 0013916517726569

Lakhan C (2015) Differences in self reported recycling behavior of first and second generation South Asians in Ontario, Canada. Resour Conserv Recycl 97:31-43. https://doi.org/10.1016/j.resconrec. 2015.02.006

Lee S, Paik HS (2011) Korean household waste management and recycling behavior. Build Environ 46:1159-1166. https://doi.org/ 10.1016/j.buildenv.2010.12.005

Lin B, Xu B (2020) How does fossil energy abundance affect China's economic growth and $\mathrm{CO} 2$ emissions? Sci Total Environ 719: 137503. https://doi.org/10.1016/j.scitotenv.2020.137503

Liu P, Teng M, Hang C (2020) How does environmental knowledge translate into pro-environmental behaviors?: the mediating role of environmental attitudes and behavioral intentions. Sci Total Environ 728:138126. https://doi.org/10.1016/j.scitotenv.2020.138126

Lo AY, Liu S (2018) Towards sustainable consumption: a socioeconomic analysis of household waste recycling outcomes in Hong Kong. J Environ Manag 214:416-425. https://doi.org/10. 1016/j.jenvman.2018.03.029

Martinho G, Magalhães D, Pires A (2017) Consumer behavior with respect to the consumption and recycling of smartphones and tablets: an exploratory study in Portugal. J Clean Prod 156:147-158. https:// doi.org/10.1016/j.jclepro.2017.04.039

MITECO (2020) Objetivos mínimos estatales y autonómicos de recogida separada de REEE para el año 2020. https://www.miteco.gob.es/es/ calidad-y-evaluacion-ambiental/temas/prevencion-y-gestionresiduos/resolucionobjetivosrecogidaraeeestatal-autonomico2020 tcm30- 507902.pdf. Accessed 1 April 2021 (in Spanish)

Nguyen HTT, Hung RJ, Lee CH, Nguyen HTT (2018) Determinants of residents' e-waste recycling behavioral intention: a case study from Vietnam. Sustainability. 11:164. https://doi.org/10.3390/ su11010164

Nixon H, Saphores JDM, Ogunseitan OA, Shapiro AA (2009) Understanding preferences for recycling electronic waste in California: the influence of environmental attitudes and beliefs on willingness to pay. Environ Behav 41:101-124. https://doi.org/10. $1177 / 0013916507310053$

Official State Gazette (2015) Real Decreto 110/2015 sobre residuos de aparatos eléctricos y electrónicos. https://www.boe.es/eli/es/rd/ 2015/02/20/110. Accessed 1 April 2021 (in Spanish)

Oskamp S, Burkhardt RL, Schultz PW, Hurin S, Zelezny L (1998) Predicting Three Dimensions of Residential Curbside Recycling: An Observational Study. J Environ Educ 29:37-42. https://doi.org/ $10.1080 / 00958969809599111$

Pausas JG, Millán M (2019) Greening and browning in a climate change hotspot: the Mediterranean Basin. BioScience 69:143-151. https:// doi.org/10.1093/biosci/biy 157

Pearson HC, Dawson LN, Radecki Breitkopf C (2012) Recycling attitudes and behavior among a clinic-based sample of low-income 
Hispanic women in southeast Texas. PLoS One 7:e34469. https:// doi.org/10.1371/journal.pone.0034469

Pérez-Belis V, Bovea MD, Ibáñez-Forés V (2015a) An in-depth literature review of the waste electrical and electronic equipment context: trends and evolution. Waste Manag Res 33:3-29. https://doi.org/ 10.1177/0734242X14557382

Pérez-Belis V, Bovea MD, Simó A (2015b) Consumer behaviour and environmental education in the field of waste electrical and electronic toys: a Spanish case study. Waste Manag 36:277-288. https://doi. org/10.1016/j.wasman.2014.10.022

Perry GDR, Williams ID (2007) The participation of ethnic minorities in kerbside recycling. A case study. Resour Conserv Recycl 49:308323. https://doi.org/10.1016/j.resconrec.2006.02.006

Purcell M, Magette WL (2010) Attitudes and behaviour towards waste management in the Dublin, Ireland region. Waste Manag 30:19972006. https://doi.org/10.1016/j.wasman.2010.02.021

Saphores JD, Ogunseitan OA, Shapiro AA (2012) Willingness to engage in a pro-environmental behavior: an analysis of e-waste recycling based on a national survey of U.S. households. Resour Conserv Recycl 60:49-63. https://doi.org/10.1016/j.resconrec.2011.12.003

Sidique SF, Lupi F, Joshi S (2010) The effects of behavior and attitude on drop-off recycling activities. Resour Conserv Recycl 54:163-170. https://doi.org/10.1016/j.resconrec.2009.07.012

Song Q, Wang Z, Li J (2012) Residents' behaviors, attitudes, and willingness to pay for recycling e-waste in Macau. J Environ Manag 106:8-16. https://doi.org/10.1016/j.jenvman.2012.03.036

Sorkun MF (2018) How do social norms influence recycling behavior in a collectivistic society? A case study from Turkey. Waste Manag 80: 359-370. https://doi.org/10.1016/j.wasman.2018.09.026

Tadesse T (2009) Environmental concern and its implications to household waste separation and disposal: evidence from Mekelle, Ethiopia. Resour Conserv Recycl 53:183-191. https://doi.org/10. 1016/j.resconrec.2008.11.009

United Nations (2015) Transforming our world: the 2030 Agenda for Sustainable Development. Retrieved from: https://www.un.org/ga/
search/view_doc.asp?symbol=A/RES/70/1\&Lang=E. Accessed 1 March 2021

Vassanadumrongdee S, Kittipongvises S (2018) Factors influencing source separation intention and willingness to pay for improving waste management in Bangkok, Thailand. Sustain. Environ Res 28:90-99. https://doi.org/10.1016/j.serj.2017.11.003

Vesely S, Klöckner CA (2018) Global Social Norms and Environmental Behavior. Environ Behav 50:247-272. https://doi.org/10.1177/ 0013916517702190

Wang Z, Zhang B, Yin J, Zhang X (2011) Willingness and behavior towards e-waste recycling for residents in Beijing city, China. J Clean Prod 19:977-984. https://doi.org/10.1016/j.jclepro.2010.09. 016

Wooldridge JM (2002) Econometric analysis of cross section and panel data. The MIT Press, Cambridge (Massachussetts)

$\mathrm{Xu}$ B, Lin B (2018) Assessing the development of China's new energy industry. Energy Econ 70:116-131. https://doi.org/10.1016/j.eneco. 2018.01.001

$\mathrm{Xu}$ L, Ling M, Wu Y (2018) Economic incentive and social influence to overcome household waste separation dilemma: a field intervention study. Waste Manag 77:522-531. https://doi.org/10.1016/j. wasman.2018.04.048

Yakob H, Abd Rauf NRA, Abdullah YA, Hoon Leh OL (2020) Factors that contribute to domestic waste recycling: a preliminary survey. Environ-Behav Proc J 5:415-422. https://doi.org/10.21834/ebpj. v5i15.2489

Zen IS, Noor ZZ, Yusuf RO (2014) The profiles of household solid waste recyclers and non-recyclers in Kuala Lumpur, Malaysia. Habitat Int 42:83-89. https://doi.org/10.1016/j.habitatint.2013.10.010

Publisher's note Springer Nature remains neutral with regard to jurisdictional claims in published maps and institutional affiliations. 